\title{
Leaf litter decomposition rates increase with rising mean annual temperature in Hawaiian tropical montane wet forests
}

Decomposing litter in forest ecosystems supplies nutrients to plants, carbon to heterotrophic soil microorganisms and is a large source of $\mathrm{CO}_{2}$ to the atmosphere. Despite its essential role in carbon and nutrient cycling, the temperature sensitivity of leaf litter decay in tropical forest ecosystems remains poorly resolved, especially in tropical montane wet forests where the warming trend may be amplified compared to tropical wet forests at lower elevations. We quantified leaf litter decomposition rates along a highly constrained $5.2{ }^{\circ} \mathrm{C}$ mean annual temperature (MAT) gradient in tropical montane wet forests on the Island of Hawaii. Dominant vegetation, substrate type and age, soil moisture, and disturbance history are all nearly constant across this gradient, allowing us to isolate the effect of rising MAT on leaf litter decomposition and nutrient release. Leaf litter decomposition rates were a positive linear function of MAT, causing the residence time of leaf litter on the forest floor to decline by $\sim 31$ days for each $1{ }^{\circ} \mathrm{C}$ increase in MAT. Our estimate of the $Q_{10}$ temperature coefficient for leaf litter decomposition was 2.17, within the commonly reported range for heterotrophic organic matter decomposition (1.5 - 2.5) across a broad range of ecosystems. The percentage of leaf litter nitrogen $(\mathrm{N})$ remaining after six months declined linearly with increasing MAT from $\sim 88 \%$ of initial $\mathrm{N}$ at the coolest site to $\sim 74 \%$ at the warmest site. The lack of net $\mathrm{N}$ immobilization during all three litter collection periods at all MAT plots indicates that N was not limiting to leaf litter decomposition, regardless of temperature. These results suggest that leaf litter decay in tropical montane wet forests may be more sensitive to rising MAT than in tropical lowland wet forests, and that increased rates of $\mathrm{N}$ release from decomposing litter could delay or prevent progressive $\mathrm{N}$ limitation to net primary productivity with climate warming. 
1 Title: Leaf litter decomposition rates increase with rising mean annual temperature in Hawaiian

2 tropical montane wet forests.

3 Lori Bothwell ${ }^{1}$, Paul C. Selmants ${ }^{2 *}$, Christian P. Giardina ${ }^{3}$ and Creighton M. Litton ${ }^{2}$

$4 \quad{ }^{1}$ Natural Sciences Division, University of Hawaii at Hilo, Hilo, HI 96720 USA

$5 \quad{ }^{2}$ Department of Natural Resources and Environmental Management, University of Hawaii at

6 Manoa, Honolulu, HI 96822 USA

$7 \quad{ }^{3}$ Institute of Pacific Islands Forestry, Pacific Southwest Research Station, USDA Forest Service,

8 Hilo, HI 96720 USA

9 *Corresponding author, email: selmants@hawaii.edu 
Introduction:

11 Litter decomposition is a fundamental biogeochemical process influencing rates of carbon

12 and nutrient cycling in forest ecosystems (Perry et al. 2008). Global syntheses indicate that

13 temperature is a primary factor controlling litter decay rates (Aerts 1997, Gholz et al. 2000, Adair

14 et al. 2008), but these datasets are dominated by temperate forest ecosystems. The factors

15 controlling litter decomposition in tropical wet forest ecosystems are less well studied (Cusack et

16 al. 2009, Wieder et al. 2009) and data from tropical montane wet forests are particularly sparse

17 (Malhi et al. 2010). The paucity of litter decomposition data from tropical montane wet forests

18 represents a significant gap in knowledge given recent evidence that litter decomposition in

19 montane tropical wet forests may be more sensitive to rising temperature than in lowland tropical

20 wet forests (Waring 2012) and that warming in the tropics may be occurring faster at higher

21 elevations (Giambelluca et al. 2008).

22 One of the more tractable approaches to estimate the temperature sensitivity of litter decay in

23 forests is through the use of elevation gradients, which can be powerful tools to examine climatic

24 controls on ecosystem functioning (Malhi et al. 2010). Observational studies along elevation

25 transects substitute space for time by examining litter decay rates in forests across a range of

26 temperature environments, and so have the advantage of representing the long-term, integrated

27 response of decomposition to changing mean annual temperature (MAT). Elevation gradients are

28 seldom a perfect proxy for climate warming, however, because other factors that influence

29 ecosystem processes may also vary with elevation, including plant species composition,

30 precipitation and soil moisture, geologic substrate, and soil chemical and physical properties.

31 These potentially confounding factors can complicate efforts to isolate the influence of

32 temperature on ecosystem functioning along elevation gradients (Wood et al. 2012). 
33 We know of only two studies that have specifically examined the effect of temperature on leaf

34 litter decomposition along elevation transects in the tropics (Scowcroft et al. 2008, Salinas et al.

35 2011), both of which indicate that temperature is a primary factor controlling leaf litter

36 decomposition rates. However, the two studies vary widely in their estimates of the apparent $Q_{10}$

37 temperature coefficient, the proportional change in litter decay rate due to a $10{ }^{\circ} \mathrm{C}$ increase in

38 temperature, potentially because of the confounding effects of precipitation and soil moisture,

39 which also exert a strong control on litter decay (Schuur 2001). For example, precipitation

40 differences with elevation in Salinas et al. (2011) resulted in a three-fold variation in mean annual

41 soil moisture across sites of different elevation. Relatively few litter decomposition studies and

42 the wide range of results from those studies highlight the need for more research aimed at

43 isolating the influence of temperature on leaf litter decay in the carbon dense and highly

44 productive tropical montane wet forest biome.

45 Here we present results of a leaf litter decomposition experiment across a well-constrained

$465.2{ }^{\circ} \mathrm{C}$ MAT gradient consisting of nine permanent plots in native-dominated tropical montane

47 wet forests spanning $800 \mathrm{~m}$ elevation along the eastern slope of Mauna Kea Volcano on the Island

48 of Hawaii. Many potentially confounding factors remain constant across this MAT gradient, such

49 as dominant canopy tree species, disturbance history, soil water content, geological substrate and

50 soil type (Litton et al. 2011, Iwashita et al. 2013, Selmants et al. 2014). We examined decay of a

51 common substrate (senescent Metrosideros polymorpha [Myrtaceae] leaves from a mid-elevation

52 plot) across the MAT gradient over a six-month time period to address two main research

53 questions: (i) Does rising MAT increase rates of leaf litter decomposition in tropical montane wet

54 forests when other environmental factors are held constant?; and (ii) does variation in MAT alter

55 the rate of nitrogen $(\mathrm{N})$ release from decomposing leaf litter in tropical montane wet forests?

56 Materials and methods: 
58 We tested the effect of rising MAT on leaf litter decomposition rates by using a highly

59 constrained MAT gradient along the eastern flank of Mauna Kea volcano on the Island of Hawaii.

60 This MAT gradient consists of nine permanent $20 \times 20 \mathrm{~m}$ plots in native-dominated tropical

61 montane wet forests spanning $800-1600 \mathrm{~m}$ in elevation, which corresponds to a $5.2{ }^{\circ} \mathrm{C}$ MAT

62 gradient $\left(13.8-18.2^{\circ} \mathrm{C}\right)$. All nine MAT plots are similar in factors other than mean annual

63 temperature that can affect ecosystem processes, including vegetation, disturbance history, soils,

64 parent material, and soil water balance (Litton et al. 2011, Iwashita et al. 2013, Selmants et al.

65 2014). Specifically, all nine MAT plots are in moderately aggrading mature forests with a canopy

66 dominated by M. polymorpha and a mid-story dominated by three species of tree fern (Cibotium

67 spp.). Soils are all well-drained Acrudoxic Hydrudands according to USDA Soil Classification

68 System, and are all derived from $\sim 20,000$ year-old volcanic ash deposits on top of a Pleistocene-

69 age lava flow dominated by the minerals hawaiite and mugearite (Wolfe and Morris 1996, Litton

70 et al. 2011). Rainfall is not constant across the MAT gradient, but tends to decrease with

71 elevation (Table 1). However, potential evapotranspiration also decreases with elevation (Table

721 ; Giambelluca et al. 2014), which results in near constant mean annual soil water content across

73 the gradient (Litton et al. 2011). Solar radiation is also nearly constant across the MAT gradient

74 (Table 1), and all MAT plots are below the trade wind inversion layer (Cao et al. 2007). The

75 seven lower elevation MAT plots are in the Hawaii Experimental Tropical Forest and were

76 accessed by permission from the USDA Forests Service and the State of Hawaii Department of

77 Land and Natural Resources. The two highest elevation MAT plots are in the Hakalau Forest

78 National Wildlife Refuge and were accessed by permission from the US Fish and Wildlife

79 Service.

80 Experimental design 
81 We examined the effect of MAT on leaf litter decomposition by following the decay of

82 senescent M. polymorpha leaves in each of the nine MAT plots for a six month period (June to

83 December, 2012). Rainfall is fairly evenly distributed throughout the year on windward slopes in

84 the Hawaiian Islands (Giambelluca et al. 2013) and seasonal changes in solar zenith angle,

85 although much less pronounced than in higher latitude temperate regions, lead to slightly warmer

86 air temperatures in summer months than in winter (Giambelluca et al. 2014).

87 We used intact senescent M. polymorpha leaves sorted from oven-dried litterfall samples

88 collected monthly in elevated trays at $1116 \mathrm{~m}\left(16.1^{\circ} \mathrm{C}\right.$; Table 1) from July 2010 through March

89 2012. These leaves were composited and well mixed for construction of individual litterbags. We

90 used litter collected from one species at a single elevation as a standard substrate to isolate the

91 effect of MAT on litter decay by minimizing variation in litter nutrient concentration. Each

92 litterbag was $10 \times 15 \mathrm{~cm}$, constructed of fiberglass screen with $1.5 \mathrm{~mm}$ mesh size and contained

$932.5 \mathrm{~g}$ of well-mixed senescent M. polymorpha leaves. We deployed 15 litterbags per MAT plot in

94 June of 2012. We placed a cluster of three litterbags tethered with nylon fishing line to a central

95 stake in five $5 \times 5 \mathrm{~m}$ subplots within each MAT plot, resulting in five replicate litterbags for each

96 collection period in each MAT plot. All litterbags were placed on the soil surface (top of the $\mathrm{O}$

97 horizon). We collected litterbags at one, three, and six months after initial placement. After each

98 collection, litter was oven-dried at $70^{\circ} \mathrm{C}$, weighed and finely ground in a ball mill for chemical

99 analysis. We did not correct for ash-free dry mass, but, because they were placed on top of the

100 undisturbed $\mathrm{O}$ horizon, there was no evidence of soil accumulation on either litterbag surfaces or

101 litter itself. Total $\mathrm{N}$ of initial, undecomposed leaf litter and of partially decomposed litter from the

102 three collection periods was determined by combustion using a Costech Elemental Analyzer at

103 the University of Hawaii at Hilo Analytical Laboratory (Costech Analytical Technologies,

104 Valencia, CA USA). 
105

106

107

108

109

110

111

112

113

\section{Data analysis}

We estimated the decomposition rate of $M$. polymorpha leaf litter for each of the five replicate litterbag clusters within each MAT plot by fitting a single-pool negative exponential model to the litter mass data (Olson 2007) using non-linear regression with initial mass fixed at the measured value (Adair et al. 2010):

$$
X(t)=e^{-k t}
$$

where $X(t)$ is the proportional mass remaining at time $t$ (in days) and $k$ is the decomposition rate. The proportional initial mass, $X(0)$, is equal to 1 by definition and so is not estimated as a model parameter (Adair et al. 2010). The mean residence time of leaf litter on the forest floor was calculated as $1 / k$ for each set of litterbags. We calculated the $\mathrm{Q}_{10}$ temperature coefficient for litter decomposition rates across the MAT gradient as:

$$
Q_{10}=\left(R_{2} / R_{1}\right)^{10 /\left(T_{2}-T_{1}\right)}
$$

Where $Q_{10}$ is the proportional change in $k$ due to a $10^{\circ} \mathrm{C}$ increase in MAT, $R_{1}$ and $R_{2}$ are regression-derived estimates of $k$ at the coolest and warmest MAT plots, and $T_{1}$ and $T_{2}$ are MAT values of the coolest and warmest MAT plots $\left(13^{\circ} \mathrm{C}\right.$ and $18.2^{\circ} \mathrm{C}$, respectively). The proportion of initial $\mathrm{N}$ remaining at the end of the six-month incubation period was calculated by dividing the mass of $\mathrm{N}$ in litter collected after six months by the mass of $\mathrm{N}$ in the initial undecomposed litter (Schuur 2001).

We used ordinary least-squares linear regression to determine whether leaf litter decomposition rate $(k)$, leaf litter residence time $(1 / k)$ and the percentage of leaf litter $\mathrm{N}$ remaining after six months varied significantly as a function of MAT. The plot $(n=9)$ was the smallest experimental unit to which the treatment (MAT) was applied, and so we use within-plot means of the five replicate litterbag clusters as the response variable for all linear regression analyses. We also used regression analysis at the plot level to determine whether annual rainfall 
129 and soil water content were significant predictors of leaf litter decay rates across the MAT

130 gradient. We calculated $95 \%$ confidence intervals of the percentage of initial $\mathrm{N}$ remaining in leaf

131 litter after one, three and six months to examine net $\mathrm{N}$ mineralization and net $\mathrm{N}$ immobilization at

132 each stage of decomposition across the MAT gradient. For all statistical tests, we set $\alpha=0.05$ and

133 confirmed that the assumptions of normality and homoscedasticity were met. All statistical

134 analyses were performed in $\mathrm{R}$ version 3.0.2 (R Core Team, 2013).

\section{Results:}

136 Leaf litter decomposition rate $(k)$ ranged from $1.67 \times 10^{-3} \mathrm{~d}^{-1}$ to $4.03 \times 10^{-3} \mathrm{~d}^{-1}$ across the MAT

137 gradient and $k$ was a positive linear function of MAT $\left(\mathrm{R}^{2}=0.65, \mathrm{p}<0.01\right)$. Decomposition rates

138 increased by $0.21 \times 10^{-3} \mathrm{~d}^{-1}$ for each $1^{\circ} \mathrm{C}$ increase in MAT. Consequently, leaf litter residence

139 time declined by 31 days for each $1^{\circ} \mathrm{C}$ increase in MAT (Fig. 1). The estimated $Q_{10}$ for leaf litter

140 decomposition was 2.17 .

141 Initial $\mathrm{N}$ concentration of mixed M. polymorpha litter was $8.5 \mathrm{mg} \mathrm{g}^{-1}$. After six months of

142 decomposition, the percentage of $\mathrm{N}$ remaining in decomposing M. polymorpha leaves declined

143 significantly as a function of increasing MAT (Fig. 2), from $\sim 88 \%$ of initial $\mathrm{N}$ at the coolest site

144 to $\sim 74 \%$ of initial $\mathrm{N}$ at the warmest site, a decline of approximately two percentage points for

145 each $1{ }^{\circ} \mathrm{C}$ increase in MAT. Nitrogen remaining in leaf litter was never significantly larger than

$146100 \%$ at any stage of decomposition within any of the nine MAT plots (Fig. 3), indicating there

147 was no net $\mathrm{N}$ immobilization in decaying leaf litter. Neither annual rainfall nor soil water content

148 during the six month experiment period (Table 1) were significant predictors of leaf litter decay

149 rates $\left(R^{2}=0.013, p=0.34\right.$ for annual rainfall; $R^{2}=0.03, p=0.67$ for soil water content $)$.

\section{Discussion:}


151 Quantifying the temperature sensitivity of leaf litter decomposition and nutrient release is

152 critical to understanding how forest ecosystem processes will respond to climate change. We used

153 a highly constrained MAT gradient to demonstrate that both mass loss and $\mathrm{N}$ release during leaf

154 litter decay increase linearly in response to rising MAT in Hawaiian tropical montane wet forests.

155 Globally, there is evidence that leaf litter decay is slowed by cool temperatures in tropical

156 montane forests (Waring 2012) and that climate warming in the tropics is occurring faster at

157 higher elevations (Bradley et al. 2004, Giambelluca et al. 2008). When combined with results

158 presented here, this evidence suggests leaf litter decomposition rates in tropical montane wet

159 forests may increase substantially with climate warming in the coming decades.

160 The rates of leaf litter decomposition reported here $\left(1.67 \times 10^{-3} \mathrm{~d}^{-1}\right.$ to $4.03 \times 10^{-3} \mathrm{~d}^{-1}$ across the

161 MAT gradient) are consistent with other studies in montane wet forests in Hawaii (Hobbie and

162 Vitousek 2000, Schuur 2001, Scowcroft et al. 2008) and well within the two orders of magnitude

163 range of $3 \times 10^{-4} \mathrm{~d}^{-1}$ to $3 \times 10^{-2} \mathrm{~d}^{-1}$ reported for tropical wet forests globally (Gholz et al. 2000,

164 Cusack et al. 2009, Waring 2012). There are a number of factors aside from temperature that can

165 affect leaf litter decomposition rates in tropical montane wet forests, most notably leaching from

166 precipitation (Wieder et al. 2009), soil oxygen availability related to soil water content (Schuur

167 2001) and leaf litter chemistry (Wieder et al. 2009, Salinas et al. 2011). By decomposing a

168 common substrate across a highly constrained MAT gradient, we were able to isolate the effect of

169 temperature by largely controlling for the effects of precipitation, soil moisture, initial litter

170 chemistry and other potential confounding factors, demonstrating a strong linear increase in leaf

171 litter decomposition rate with rising MAT. This increase in leaf litter decay rate is in line with,

172 and likely contributes to, the substantial increase in soil-surface $\mathrm{CO}_{2}$ efflux across this MAT

173 gradient (Litton et al. 2011). Notably, soil organic carbon storage remains constant across the

174 MAT gradient despite increased rates of litter decay and soil-surface $\mathrm{CO}_{2}$ efflux with rising MAT

175 (Selmants et al. 2014, Giardina et al. 2014). 
176 The $Q_{10}$ temperature coefficient, which describes the rate of change in a biological or

177 chemical process over a $10^{\circ} \mathrm{C}$ interval, often falls within the range of $1.5-2.5$ when applied to

178 heterotrophic processes such as organic matter decomposition (Reiners 1968, Kätterer et al. 1998,

179 Gholz et al. 2000, Hyvönen et al. 2005, Zhou et al. 2009). Our $Q_{10}$ estimate for leaf litter

180 decomposition (2.17) is within this range, and is similar to the $Q_{10}$ estimate for soil-surface $\mathrm{CO}_{2}$

181 efflux (2.26) across the same MAT gradient (Litton et al. 2011), suggesting a consistent response

182 of carbon cycling rates to rising temperature in tropical montane wet forests. In contrast to our

183 results, Salinas et al. (2011) estimated a $Q_{10}$ for leaf litter decay of 3.06 in five tropical forest

184 plots across an elevation gradient spanning $12.8^{\circ} \mathrm{C}\left(11.1-23.9^{\circ} \mathrm{C}\right)$. Although there is wide

185 variation in estimates of apparent $Q_{10}$ from litter decomposition studies (Gholz et al. 2000, Adair

186 et al. 2008), we suggest the Salinas et al. (2011) estimate of litter decay $Q_{10}$ is $\sim 40 \%$ higher than

187 ours largely because of confounding factors related to site selection and data analysis technique.

188 First, the lowest temperature site in the Salinas et al. (2011) study was also the driest, with a

189 mean annual soil moisture nearly three-fold lower than the mean of the other four sites,

190 potentially depressing $k$ for this low temperature site. In contrast, mean annual soil moisture is

191 nearly constant across our MAT gradient (Litton et al. 2011). Although there was some variation

192 in soil water content among our MAT plots during the six-month period when leaf litter was

193 decomposing, the driest plots during the experiment period were in the middle of our gradient

194 and the percentage variation in soil moisture was an order of magnitude less than that of Salinas

195 et al. (2011). Second, Salinas et al. (2011) used linear regression of log-transformed mass loss

196 data to estimate decomposition rates, which can result in sizable overestimates of $k$ depending on

197 error structure (Adair et al. 2010). We used non-linear regression of untransformed

198 decomposition data, which consistently yields accurate $k$ estimates (Adair et al. 2010). The

199 potential confounding effect of a three-fold variation in soil moisture combined with the use of 
200 log-transformed mass loss data in the Salinas et al. (2011) study suggest that their estimate of 201 apparent $Q_{10}$ may be artificially inflated.

202 We found no evidence of $\mathrm{N}$ limitation to leaf litter decomposition across the MAT gradient.

203 At all stages of decomposition, the proportion of initial $\mathrm{N}$ remaining in decomposing leaf litter

204 never significantly exceeded $100 \%$ at any of the MAT plots. This evidence is consistent with

205 results from a fertilization experiment at a site near the middle of our MAT gradient, in which

206 individual additions of $\mathrm{N}$ and phosphorus (P) had no effect on M. polymorpha leaf litter

207 decomposition and combined $\mathrm{N}$ and $\mathrm{P}$ additions had only a weak positive effect (Hobbie and

208 Vitousek 2000). We also found an overall trend of increased rates of $\mathrm{N}$ release from decomposing

209 litter with rising MAT. Taken together, this evidence suggests that warming will increase rates of

$210 \mathrm{~N}$ cycling and availability in these forests, a response consistent with results from warming

211 experiments across a wide range of forest and grassland ecosystems (Rustad et al. 2001). We did

212 not measure leaf litter phosphorus (P) dynamics in this study, so it remains unclear how rates of $\mathrm{P}$

213 release from decomposing leaf litter respond to rising MAT. However, since P does not directly

214 limit M. polymorpha leaf litter decomposition at a site near the middle of our gradient (Hobbie

215 and Vitousek 2000), we consider it likely that increasing rates of leaf litter decay with rising MAT

216 will increase rates of $\mathrm{P}$ release and availability similar to the trend for $\mathrm{N}$ documented here.

217 Results from this leaf litter decomposition experiment across a well-constrained MAT

218 gradient have two potentially countervailing implications for how the carbon balance of tropical

219 montane wet forests will respond to climate warming, at least within the MAT range studied here

220 and where increasing temperature does not drive significant, concomitant changes in leaf litter

221 chemistry or soil water balance. First, our results indicate that warming will increase rates of leaf

222 litter decay in tropical montane wet forests, which explains part of the warming-induced increase

223 in rates of soil-surface $\mathrm{CO}_{2}$ efflux to the atmosphere (Litton et al. 2011). At the same time, these

224 results suggest that more rapid decomposition with warming should also increase rates of nutrient 
225

226

227

228

229

230

231

232

233

234

235

236

237

238

239

240

241

242

243

244

245

246

247

248

release from decaying leaf litter, at least in forest ecosystems where decomposition is not

currently nutrient limited. The availability of nutrients may strongly regulate whether ecosystem

carbon sequestration keeps pace with rising atmospheric $\mathrm{CO}_{2}$ concentrations (Luo et al. 2004).

An increase in rates of nutrient release from decaying leaf litter with climate warming, as

suggested by our results, could delay or even prevent the onset of progressive nutrient limitation

of ecosystem carbon sequestration.

\section{Acknowledgements:}

Thanks to Kupu Hawaii Youth Conservation Corps interns Nathanael Friday and Isaac Ito for assistance with data collection.

\section{References:}

Adair, E. C., S. E. Hobbie, and R. K. Hobbie. 2010. Single-pool exponential decomposition models: potential pitfalls in their use in ecological studies. Ecology 91:1225-1236.

Adair, E. C., W. J. Parton, S. J. del Grosso, W. L. Silver, M. E. Harmon, S. A. Hall, I. C. Burke, and S. C. Hart. 2008. Simple three-pool model accurately describes patterns of long-term litter decomposition in diverse climates. Global Change Biology 14:2636-2660.

Aerts, R. 1997. Climate, leaf litter chemistry and leaf litter decomposition in terrestrial ecosystems: a triangular relationship. Oikos:439-449.

Bradley, R. S., F. T. Keimig, and H. F. Diaz. 2004. Projected temperature changes along the American cordillera and the planned GCOS network. Geophysical Research Letters 31:L16210.

Cao, G., T. W. Giambelluca, D. E. Stevens, and T. A. Schroeder. 2007. Inversion Variability in the Hawaiian Trade Wind Regime. Journal of Climate 20:1145-1160.

Cusack, D. F., W. W. Chou, W. H. Yang, M. E. Harmon, W. L. Silver, The LIDET Team. 2009. Controls on long-term root and leaf litter decomposition in neotropical forests. Global 
Gholz, H. L., D. A. Wedin, S. M. Smitherman, M. E. Harmon, and W. J. Parton. 2000. Long-term

251 dynamics of pine and hardwood litter in contrasting environments: toward a global model of 252 decomposition. Global Change Biology 6:751-765.

253 Giambelluca, T. W., H. F. Diaz, and M. S. A. Luke. 2008. Secular temperature changes in

254 Hawai'i. Geophysical Research Letters 35:L12702.

255 Giambelluca, T. W., Q. Chen, A. G. Frazier, J. P. Price, Y.-L. Chen, P.-S. Chu, J. K. Eischeid, and 256 D. M. Delparte. 2013. Online Rainfall Atlas of Hawai'i. Bulletin of the American

257 Meteorological Society 94:313-316.

258 Giambelluca, T. W., X. Shuai, M. L. Barnes, R. J. Aliss, R. J. Longman, T. Miura, Q. Chen, A. G.

259 Frazier, R. G. Mudd, L. Cuo, and A. D. Businger. 2014. Evapotranspiration of Hawai'i. Pages $260 \quad 1-178$.

261 Giardina, C. P., C. M. Litton, S. E. Crow, and G. P. Asner. 2014. Warming-related increases in 262 soil $\mathrm{CO} 2$ efflux are explained by increased below-ground carbon flux. Nature Climate 263 Change.

264 Hobbie, S. E., and P. M. Vitousek. 2000. Nutrient limitation of decomposition in Hawaiian 265 forests. Ecology 81:1867-1877.

266 Hyvönen, R., G. I. Ågren, and P. Dalias. 2005. Analysing temperature response of decomposition 267 of organic matter. Global Change Biology 11:770-778.

268 Iwashita, D. K., C. M. Litton, and C. P. Giardina. 2013. Coarse woody debris carbon storage 269 across a mean annual temperature gradient in tropical montane wet forest. Forest Ecology 270 and Management 291:336-343.

271 Kätterer, T., M. Reichstein, O. Andrén, and A. Lomander. 1998. Temperature dependence of 272 organic matter decomposition: a critical review using literature data analyzed with different 273 models. Biology and fertility of soils 27:258-262. 
274 Litton, C. M., C. P. Giardina, J. K. Albano, M. S. Long, and G. P. Asner. 2011. The magnitude

275 and variability of soil-surface $\mathrm{CO}_{2}$ efflux increase with mean annual temperature in Hawaiian

276 tropical montane wet forests. Soil Biology and Biochemistry 43:2315-2323.

277 Luo, Y., B. Su, W. S. Currie, J. S. Dukes, A. C. Finzi, U. Hartwig, B. A. Hungate, R. E.

278 McMurtrie, R. Oren, W. J. Parton, D. E. Pataki, R. Shaw, D. R. Zak, and C. B. Field. 2004.

279 Progressive Nitrogen Limitation of Ecosystem Responses to Rising Atmospheric Carbon

$280 \quad$ Dioxide. BioScience 54:731-739.

281 Malhi, Y., M. Silman, N. Salinas, M. BUSH, P. Meir, and S. Saatchi. 2010. Introduction:

282 Elevation gradients in the tropics: laboratories for ecosystem ecology and global change

283 research. Global Change Biology 16:3171-3175.

284 Olson, J. S. 2007. Energy storage and the balance of producers and decomposers in ecological $285 \quad$ systems. Ecology 44:322-331.

286 Perry, D. A., R. Oren, and S. C. Hart. 2008. Forest Ecosystems. Second edition. Johns Hopkins

287 University Press, Baltimore, MD.

288 Reiners, W. A. 1968. Carbon dioxide evolution from the floor of three Minnesota forests. Ecology $289 \quad 49: 471-483$.

290 Rustad, L. E., J. L. Campbell, G. M. Marion, R. J. Norby, M. J. Mitchell, A. E. Hartley, J. H. C.

291 Cornelissen, J. Gurevitch, and N. A. Not Available. 2001. A meta-analysis of the response of 292 soil respiration, net nitrogen mineralization, and aboveground plant growth to experimental 293 ecosystem warming. Oecologia 126:543-562.

294 Salinas, N., Y. Malhi, P. Meir, M. Silman, R. Roman Cuesta, J. Huaman, D. Salinas, V. Huaman, 295 A. Gibaja, M. Mamani, and F. Farfan. 2011. The sensitivity of tropical leaf litter

296 decomposition to temperature: results from a large-scale leaf translocation experiment along 297 an elevation gradient in Peruvian forests. New Phytologist 189:967-977.

298 Schuur, E. A. G. 2001. The effect of water on decomposition dynamics in mesic to wet Hawaiian 
montane forests. Ecosystems 4:259-273.

300 Scowcroft, P., D. R. Turner, and P. M. Vitousek. 2008. Decomposition of Metrosideros

301 polymorpha leaf litter along elevational gradients in Hawaii. Global Change Biology 6:73-

$302 \quad 85$.

303 Selmants, P. C., C. M. Litton, C. P. Giardina, and G. P. Asner. 2014. Ecosystem carbon storage

304 does not vary with mean annual temperature in Hawaiian tropical montane wet forests.

305 Global Change Biology 20:2927-2937.

306 Waring, B. G. 2012. A Meta-analysis of Climatic and Chemical Controls on Leaf Litter Decay

307 Rates in Tropical Forests. Ecosystems 15:999-1009.

308 Wieder, W. R., C. C. Cleveland, and A. R. Townsend. 2009. Controls over leaf litter

309 decomposition in wet tropical forests. Ecology 90:3333-3341.

310 Wolfe, E. W., and J. Morris. 1996. Geologic Map of the Island of Hawaii. U.S. Geological

311 Survey, Reston, VA.

312 Wood, T. E., M. A. Cavaleri, and S. C. Reed. 2012. Tropical forest carbon balance in a warmer

313 world: a critical review spanning microbial- to ecosystem-scale processes. Biological

314 Reviews 87:912-927.

315 Zhou, T., P. Shi, D. Hui, and Y. Luo. 2009. Global pattern of temperature sensitivity of soil

316 heterotrophic respiration (Q 10) and its implications for carbon-climate feedback. Journal of

$317 \quad$ Geophysical Research 114:G02016. 
Table 1 (on next page)

Environmental characteristics of the nine permanent plots along a $5.2{ }^{\circ} \mathrm{C}$ mean annual temperature gradient in tropical montane wet forests on the Island of Hawaii.

aMean annual air temperature and mean annual soil volumetric water content from Litton et al. (2011).

${ }^{b}$ Mean monthly soil volumetric water content during the leaf litter decomposition experiment (June to December, 2012).

'Mean annual rainfall estimates from Giambelluca et al. (2013)

'Mean annual potential evapotranspiration and solar radiation estimates from Giambelluca et al. (2014). 


\begin{tabular}{|c|c|c|c|c|c|c|c|}
\hline $\begin{array}{l}\text { MAT } \\
\text { Plot }\end{array}$ & $\begin{array}{l}\text { Elevation } \\
\quad(\mathrm{m})\end{array}$ & $\begin{array}{l}\text { Air temperature } \\
\qquad\left({ }^{\circ} \mathrm{C}\right)^{\mathrm{a}}\end{array}$ & $\begin{array}{l}\text { Rainfall } \\
\left(\mathrm{mm} \mathrm{y}^{-1}\right)^{\mathrm{b}}\end{array}$ & $\begin{array}{l}\text { Soil VWC: } \\
\text { annual }\left(\mathrm{m}^{3} \mathrm{~m}^{-3}\right)^{\mathrm{a}}\end{array}$ & $\begin{array}{c}\text { Soil VWC: } \\
\text { experiment }\left(\mathrm{m}^{3} \mathrm{~m}^{-3}\right)^{\mathrm{b}}\end{array}$ & $\begin{array}{c}\text { Potential } \\
\text { evapotranspiration } \\
\left(\mathrm{mm} \mathrm{y}^{-1}\right)^{\mathrm{c}}\end{array}$ & $\begin{array}{l}\text { Solar radiation } \\
\left(\mathrm{W} \mathrm{m}^{-2} \mathrm{y}^{-1}\right)^{\mathrm{c}}\end{array}$ \\
\hline 1 & 800 & 18.2 & 4570 & 0.55 & 0.67 & 2298 & 201.1 \\
\hline 2 & 934 & 17.3 & 4292 & 0.55 & 0.64 & 2232 & 200.9 \\
\hline 3 & 1024 & 16.7 & 3975 & 0.57 & 0.63 & 2214 & 202.4 \\
\hline 4 & 1116 & 16.1 & 3734 & 0.48 & 0.61 & 2127 & 204.9 \\
\hline 5 & 1116 & 16.1 & 3433 & 0.51 & 0.47 & 2137 & 210.1 \\
\hline 6 & 1204 & 15.5 & 3181 & 0.40 & 0.42 & 2211 & 214.5 \\
\hline 7 & 1274 & 15.1 & 3101 & 0.51 & 0.44 & 2234 & 216.2 \\
\hline 8 & 1468 & 13.8 & 4119 & 0.55 & 0.61 & 1888 & 202.6 \\
\hline 9 & 1600 & 13.0 & 3282 & 0.57 & 0.60 & 1961 & 213.1 \\
\hline
\end{tabular}


Figure 1 (on next page)

Leaf litter residence time across a mean annual temperature gradient on the Island of Hawaii. 


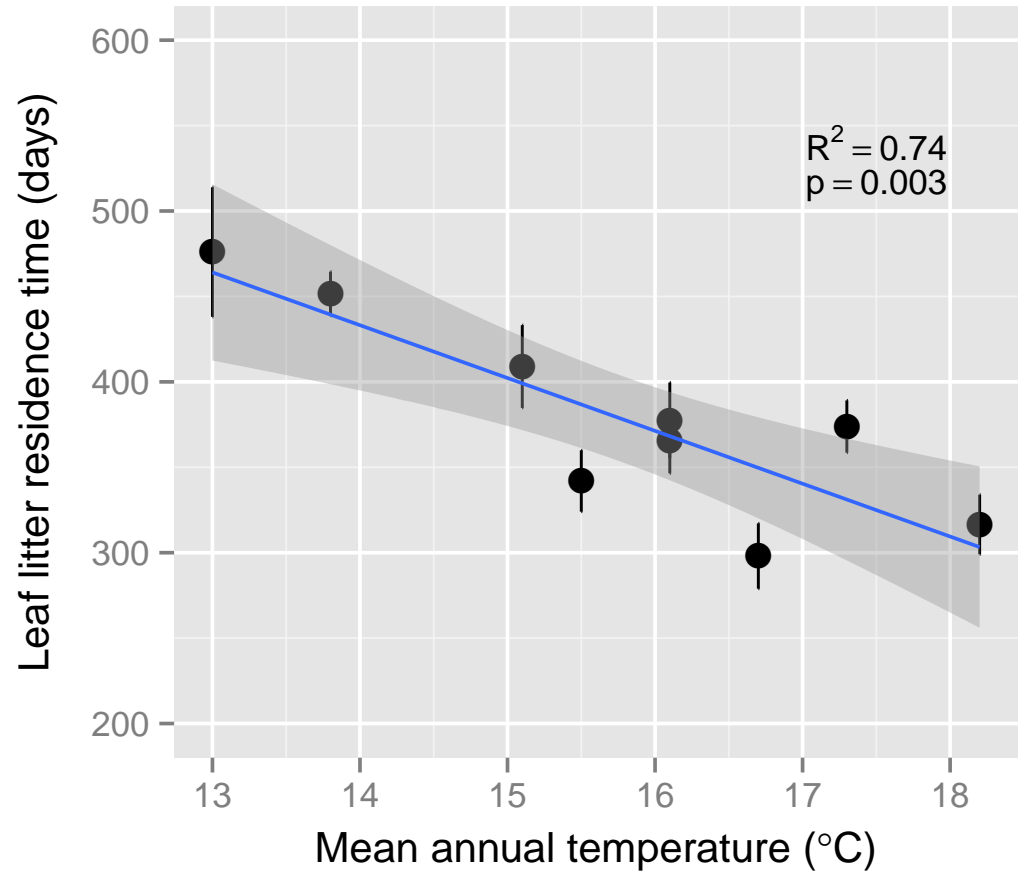


Figure 2 (on next page)

Nitrogen remaining in leaf litter after six months of decomposition across a mean annual temperature gradient on the Island of Hawaii. 


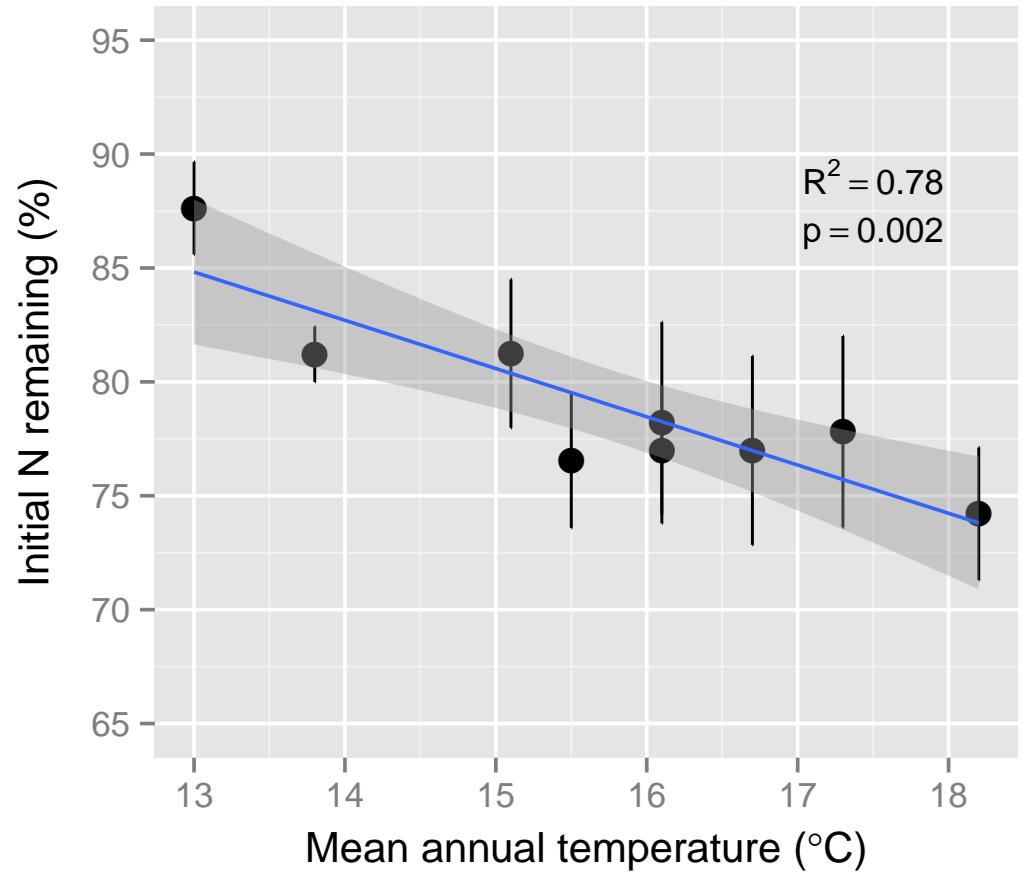


Figure 3 (on next page)

Nitrogen remaining in decomposing leaf litter at three stages of decomposition across a mean annual temperature gradient on the Island of Hawaii. 
